\title{
Abnormal Foraging Behavior Induced by Sublethal Dosage of Imidacloprid in the Honey Bee (Hymenoptera: Apidae)
}

\author{
E. C. YANG,${ }^{1,2,3}$ Y. C. CHUANG,${ }^{1}$ Y. L. CHEN,${ }^{1}$ AND L. H. CHANG ${ }^{2}$
}

\begin{abstract}
J. Econ. Entomol. 101(6): 1743-1748 (2008)
ABSTRACT Although sublethal dosages of insecticide to nontarget insects have never been an important issue, they are attracting more and more attention lately. It has been demonstrated that low dosages of the neonicotinoid insecticide imidacloprid may affect honey bee, Apis mellifera L., behavior. In this article, the foraging behavior of the honey bee workers was investigated to show the effects of imidacloprid. By measuring the time interval between two visits at the same feeding site, we found that the normal foraging interval of honey bee workers was within $300 \mathrm{~s}$. However, these honey bee workers delayed their return visit for $>300 \mathrm{~s}$ when they were treated orally with sugar water containing imidacloprid. This time delay in their return visit is concentration-dependent, and the lowest effective concentration was found to be $50 \mu \mathrm{g} /$ liter. When bees were treated with an imidacloprid concentration higher than $1,200 \mu \mathrm{g} /$ liter, they showed abnormalities in revisiting the feeding site. Some of them went missing, and some were present again at the feeding site the next day. Returning bees also showed delay in their return trips. Our results demonstrated that sublethal dosages of imidacloprid were able to affect foraging behavior of honey bees.
\end{abstract}

KEY WORDS sublethal dosage, imidacloprid, honey bee, foraging behavior

Sublethal effects have been understudied, but it has drawn more attention recently (Thompson 2003, Desneux et al. 2007). Ignorance of sublethal measurements of traditional lethal aspects of insecticides, i.e., $\mathrm{LD}_{50}$ or $\mathrm{LC}_{50}$, will definitely result in the underestimation of the chronic effects on nontarget or beneficial insects. There is a great deal of concern over the decline of the honey bee, Apis mellifera L., across the world. It has been termed colony collapse disorder, and it might be attributable to the large-scale application of neonicotinoid insecticides, such as imidacloprid, thiamethoxam, and clothianidin (Chauzat et al. 2006, Cutler and Scott-Dupree 2007, Ho and Cummins 2007, Oldroyd 2007). Because the residues of these insecticides have been detected in the samples from the nectar pollen, plant tissues, and soils (Curé et al. 2000, Schmuck et al. 2001, Bonmatin et al. 2003), it has been assumed that the homing ability of bee foragers may be severely affected by these insecticide residues collected in polluted fields, thereby jeopardizing the survival of the colony. However, without clear behavioral evidence, especially any abnormalities caused by nonacute pesticides, it is difficult to quantify the sublethal effects on the insects.

To assess the sublethal effect of pesticides on the honey bee, methodologies with both physiological and behavioral experiments have been developed (Pham-

\footnotetext{
${ }^{1}$ Department of Entomology, National Chung Hsing University, Taichung, Taiwan.

${ }^{2}$ Department of Entomology, National Taiwan University, Taipei, Taiwan.

${ }^{3}$ Corresponding author, e-mail: ecyang@ntu.edu.tw.
}

Delègue et al. 2002, Thompson 2003, Desneux et al. 2007). Imidacloprid is a neonicotinoid insecticide, which acts as an agonist of acetylcholine (ACh) to occupy the binding site of ACh nicotinic receptors in the central nervous system. Kirchner (1999) and Schmuck (1999) found that the treatment of foragers with imidacloprid affected the communication of the waggle dance performed by foragers, suggesting that the signal transmission of their motor neurons could be impaired by the insecticide. They found that only $20 \mathrm{ppb}$ imidacloprid was enough to decrease the foraging activity in honey bee colonies and that the foraging behavior was suppressed at levels above 100 ppb after 30-60 min. Transitory disruptions of foraging activity were observed at doses above $50 \mathrm{ppb}$, and they persisted overnight at doses of $100 \mathrm{ppb}$ (Schmuck 1999). A behavioral study by Bortolotti et al. (2003) demonstrated that honey bee workers were confused and disoriented if they were treated with imidacloprid. A sub-lethal dose of imidacloprid in sucrose solution affects homing and foraging activity of honey bees, and only 500 or $1,000 \mathrm{ppb}$ insecticide in sucrose solutions was sufficient to cause the workers to fail to return to the hive or to the feeding site. In addition, an imidacloprid solution as low as $100 \mathrm{ppb}$ was able to delay honey bee workers from returning to their hive or feeding site for up to $24 \mathrm{~h}$. Besides, impairment of the olfactory memory by imidacloprid was demonstrated to occur at the level of the mushroom body (Decourtye et al. 2004b), which is essential in olfactory memory (Fahrbach 2006). 
In the present research, we observed the behavior of foragers caused by the oral ingestion of an imidacloprid-treated sugar solution. We measured the time interval between two visits to the same feeding site. Our experiments demonstrated that the foraging activity of the honey bee is temporally constant under normal circumstances. However, foragers delay their revisiting of the feeding site or even disappear if they suffer poison stress at the feeding place. This result is consistent with the conclusions of previous sublethal dosage-effect studies, suggesting that the time interval measurement can be added to the list of assessment methods to determine the sublethal effects of a pesticide.

\section{Materials and Methods}

Animals. Three colonies of honey bee that were raised on the campus of National Chung Hsing University in Taiwan were used for the behavioral experiments. Honey bee foragers were trained to fly to an artificial feeder, and they were gradually attracted to an experimental station that was $\approx 35 \mathrm{~m}$ away from the beehives, so as to establish a fixed flying pathway between the beehives and the feeding site. The artificial feeder was filled with $50 \%$ sucrose solution (wt: vol) to keep bees coming regularly.

Preparation of Insecticide. Imidacloprid (95\% TG, Bayer Cropscience AG, Leverkusen, Germany) was prepared in 12 stock solutions between 40 and 6,000 $\mathrm{mg} /$ liter in acetone (>99.5\%; LCY Chemical Co., Taipei, Taiwan) or dimethyl sulfoxide (DMSO, MP Biomedicals, Irvine, CA). The stock solutions were stored at $4^{\circ} \mathrm{C}$, and they were diluted to a final concentration between 40 and $6,000 \mu \mathrm{g} /$ liter in $50 \%$ sucrose solution before each experiment. The final concentration of solvent in the sucrose solution was equal to $0.1 \%$ (vol:vol).

Experimental Procedures. On the artificial feeder, bee foragers were individually labeled with various colors painted on the dorsal surface of the thorax. The time interval of labeled bees rewarded $(\mathrm{T})$ was recorded continuously for $1 \mathrm{~h}$. The time interval is defined as the time between the rewarded honey bee flying out of the feeding site and her next visit to the same feeding site. In $1 \mathrm{~h}$ of rewards, the bees showed normal foraging behavior, and their visits to the feeding site were regular if they were not disturbed. Then, the artificial feeder was replaced with a feeder of sucrose solution containing imidacloprid. After feeding the imidacloprid solution once, the artificial feeder was replaced again by a feeder without imidacloprid, and the feeding intervals were continuously recorded for $1.5 \mathrm{~h}$. Following the same procedure, groups of bees were individually fed with different concentrations of imidacloprid. All experiments were carried out from 1000 to 1600 hours on sunny days only from May 2006 to March 2007. During the experiments, the outdoor temperature was recorded, and the dynamic range was $22.6 \approx 32.8^{\circ} \mathrm{C}$. The foraging behavior was normal, and no behavioral changes caused by temperature dynamics were observed.

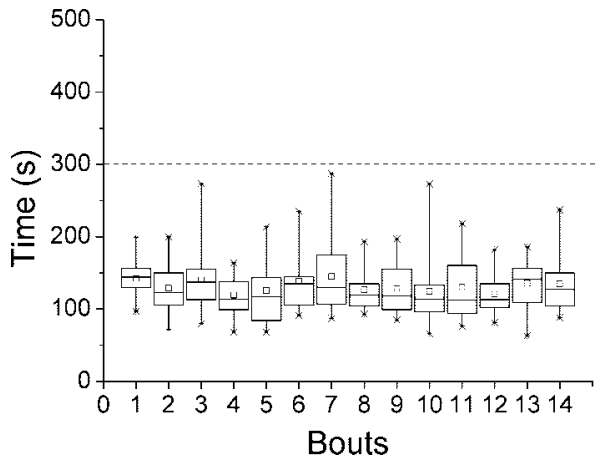

Fig. 1. Time interval of honey bee workers between two visits to the feeding site $(\mathrm{T})$. Each of the box-charts shows the data information of $\mathrm{T}$ for each bout. The asterisk (*) represents the maximum and minimum of the recorded $\mathrm{T}$ on each bout; the central square indicates the average of $\mathrm{T}$ on each bout; the upper, middle and lower lines of the box indicate the 75,50 , and $25 \%$ of $\mathrm{T}$, respectively. The dotted line indicates $\mathrm{T}=300 \mathrm{~s}$, which is used as the threshold for evaluation of behavioral abnormality $(\mathrm{T}>300)$. $(n=18)$.

Statistical Analysis. In all the treatments, the number of abnormal bees between, before and after treatment in each bout was analyzed by the Wilcoxon rank sum test in SAS version 9.1.3 (SAS Institute, Cary, NC). In the imidacloprid treatment, the statistical analyses for the ratio of behavioral abnormality at each concentration were expressed as a percentage: mean $(\%) \pm \mathrm{SE}$. In addition, the multiple comparisons after analysis of variance (ANOVA) were analyzed using Scheffé test in SAS.

\section{Results}

Interval between Two Visits to Feeding Site. Without any treatment or disturbance, i.e., under normal circumstances, it was found that in the 14 occasions of flying between the beehive and the feeding site, the time interval between two successive visits to the same feeding site was consistently within $300 \mathrm{~s}(\mathrm{~T}<300 \mathrm{~s})$ and $\mathrm{T} \cong 150 \mathrm{~s}$ in average $=18$ ) (Fig. 1 ). Therefore, the honey bee's normal foraging behavior was defined as $\mathrm{T}<300 \mathrm{~s}$.

Effects of Solvents. To avoid and eliminate the effect caused by solvents, the solvent used for dissolving the imidacloprid powder should not cause any abnormality on the honey bee feeding behavior. Because imidacloprid is easily dissolved in both acetone and DMSO, experiments were conducted to reveal behavioral abnormality for this purpose. The time intervals of 11 feeding trips before treatment were recorded, and all the bees (acetone, $n=19$; DMSO, $n=20$ ) showed $\mathrm{T}<300 \mathrm{~s}$ as expected (Fig. $2 \mathrm{~A}$ and $\mathrm{C}$ ). Then, the bees were fed with sugar solution with acetone or DMSO. Acetone and DMSO solutions (0.1\%, vol:vol) were made in $50 \%$ sugar solutions, and both the solutions were accepted by the bee foragers. None of the bees tested in this experiment showed antifeeding behavior, and they were able to land on the artificial feeder for sucking the sucrose solution containing 

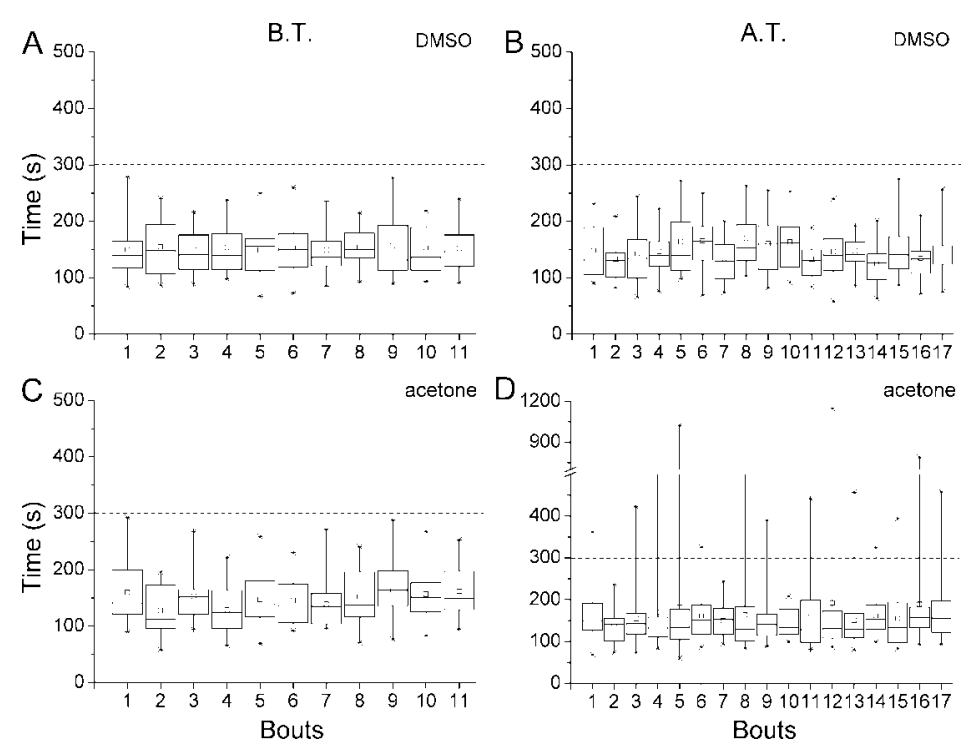

Fig. 2. Evaluation of the effects induced by different solvents used to dissolve imidacloprid. The honey bee workers were fed $50 \%$ sugar water containing $0.1 \%$ (vol:vol) DMSO or acetone. (A and B) Before and after feeding on sugar water containing DMSO, respectively $(n=20)$. (C and D) before and after feeding on sugar water containing acetone, respectively $(n=19)$.

acetone or DMSO. Most of the bees came back regularly to visit the feeder with $\mathrm{T} \cong 150 \mathrm{~s}$, on average (Fig. 2B and D). However, the number of abnormal bees between, before and after acetone treatment showed a significant difference (Fig. 2C and D, $Z=$ $-4.0311, P<0.0001$ ), indicating that the reward behavior of the bees might be influenced by acetone. Therefore, DMSO was chosen as the solvent for making the stock solution of our next experiments.

Effects of Imidacloprid Treatment. Honey bees that showed normal foraging behavior and regularly visited the feeding site with $\mathrm{T}<300 \mathrm{~s}$ were used for testing the effects of imidacloprid. By feeding them sugar solutions with different concentrations of imidacloprid, the bees showed abnormal foraging behavior (i.e., $\mathrm{T}>300 \mathrm{~s}$ ) when the concentration was beyond $50 \mu \mathrm{g} /$ liter (Fig. 3). At concentrations of 50, 100, 200, 400,600 , and $800 \mu \mathrm{g} /$ liter, the percentages of abnormal foraging behavior were $15.2 \pm 4.4,36.7 \pm 11.6,33.5 \pm$ $12.8,74.1 \pm 13.3,78.5 \pm 8.8$, and $83.3 \pm 8.3 \%$ respectively. At concentrations higher than 1,200 $\mu \mathrm{g}$ / liter, all the bees showed abnormal foraging behavior after imidacloprid treatment (Fig. 3). This dosage-dependent behavioral abnormality demonstrates that the rewarding behavior of honey bees is affected by imidacloprid, even if the concentration is much lower than the $\mathrm{LD}_{50}$ reported previously (Elbert et al. 1991; Suchail et al. 2000, 2001; Nauen et al. 2001; Schmuck et al. 2001; Decourtye et al. 2003). To estimate the dosage the bees might uptake from the imidacloprid in sucrose solution, the meal sizes of bees were measured with spectroscopic quantification of Rose Bengaldyed sucrose solution. We found that the meal size range $(n=12)$ was from 36.3 to $86.5 \mu \mathrm{l}$ per bee (unpublished data), indicating that the behavioral abnormality could be induced by the dosage as low as $1.82 \approx 4.33$ ng per bee.
Some bees did not return to the feeding site after treatment for at least $1.5 \mathrm{~h}$. At concentrations of 600 , $800,1,200$, and $3,000 \mu \mathrm{g} /$ liter, the percentages of missing bees were $34.4,50,68,93.3$, and $96.9 \%$, respectively (Fig. 4). At concentration of 4,000 and 6,000 $\mu \mathrm{g} /$ liter, all the bees were missing. We continuously recorded the bees that came back to the feeding site the next day, and found that the bees could recover $100 \%$ at concentrations lower than $1,600 \mu \mathrm{g}$ / liter but only 77.4 , 63.6 , and $48.4 \%$ of the missing bees returned to the feeding site at $3,000,4,000$, and $6,000 \mu \mathrm{g} /$ liter, respectively (Fig. 5 ). The bee's ability to recover decreased when the concentration of imidacloprid increased. In addition, although some of the missing bees returned the next day to the feeding site, some of them did not

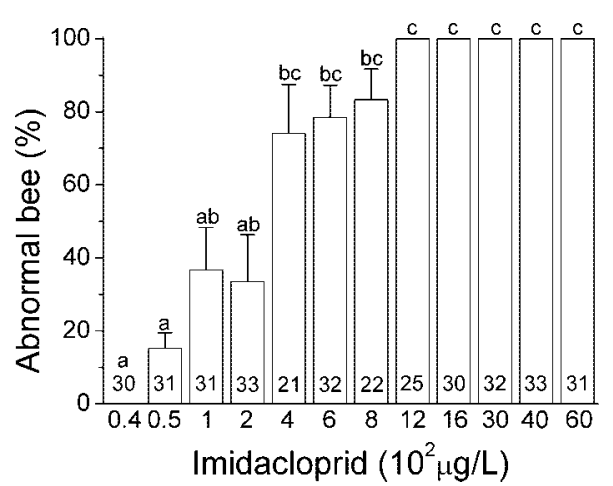

Fig. 3. The ratio of behavioral abnormality $(\mathrm{T}>300 \mathrm{~s})$ induced by imidacloprid. The honey bee workers were fed sugar water containing different concentrations of imidacloprid. The testing concentrations of imidacloprid were 40,50 , $100,200,400,600,800,1,200,1,600,3,000,4,000$, and 6,000 $\mu \mathrm{g} /$ liter. The number on each bar indicates the sample size (n) for each testing concentration. 


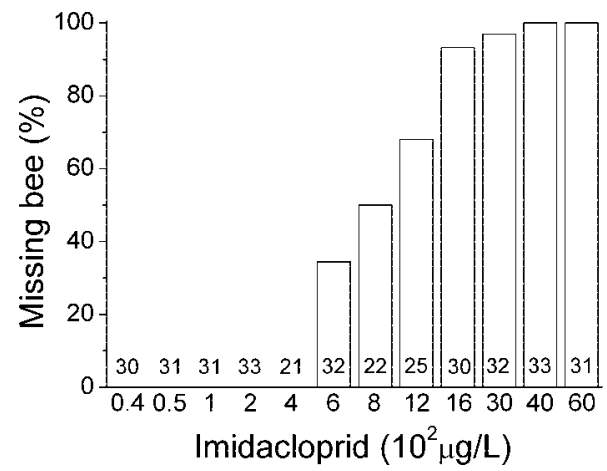

Fig. 4. The ratio of missing bees after feeding on $50 \%$ sugar water containing different concentrations of imidacloprid. The testing concentrations of imidacloprid are shown in Fig. 3. The number on each bar indicates the number of bees treated for each testing concentration.

present themselves regularly at the feeding site like they did before treatment. The foraging behavior of the returned bees was irregular and significantly different from the foraging behavior before treatment (Fig. 6, $Z=-2.7998, P<0.0051$ ), indicating that the returning bees still suffered from imidacloprid poisoning.

At the same time, some tested bees were not immediately affected by the imidacloprid after the treatment. We monitored the bees to see the start of abnormal foraging behavior after feeding imidacloprid sugar solution. The result showed that the access timing of behavioral abnormality (i.e., $\mathrm{T}>300$ ) is also dosage-dependent (Fig. 7). At concentrations of 50 and $600 \mu \mathrm{g}$ / liter, the abnormality was irregularly distributed during the 90 min of observation but did not occur immediately after treatment. The bees started their abnormal behavior past $20 \mathrm{~min}$ after $50 \mu \mathrm{g} /$ liter imidacloprid treatment and $10 \mathrm{~min}$ after $100 \mu \mathrm{g} /$ liter treatment. When the concentration was increased to $200 \mu \mathrm{g} /$ liter or more, the bees started their abnormal

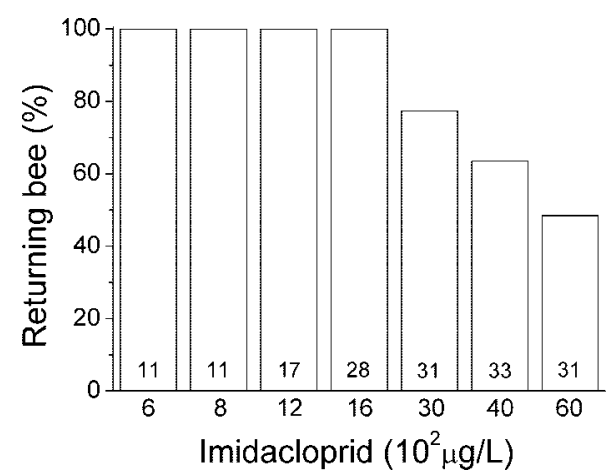

Fig. 5. The returning ratio of missing bees the next day after imidacloprid treatment. The testing concentrations of imidacloprid are shown in Fig. 3. The number on each bar indicates the number of missing bees on the first day after being treated with imidacloprid for each testing concentration.

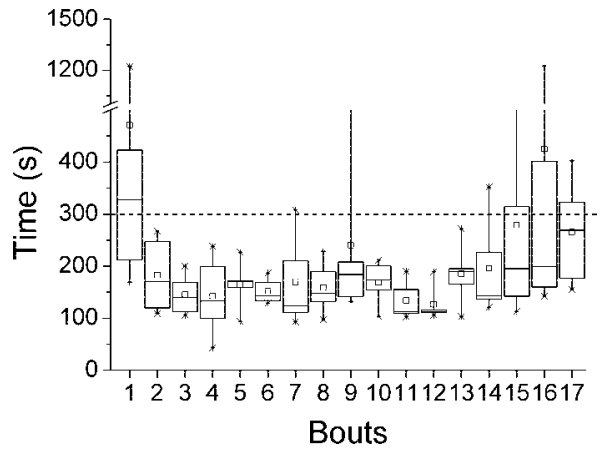

Fig. 6. Behavioral abnormality of the returning bees $(n=$ 5), which were treated with 1,200 $\mu \mathrm{g}$ / liter imidacloprid (in $50 \%$ sugar water solution) and which were missing on the first day. Each of the box-chart shows the data information of $\mathrm{T}$ for each bout, as shown in Fig. 1. The dotted line indicates $\mathrm{T}=300 \mathrm{~s}$, which is used as the threshold for evaluation of behavioral abnormality $(\mathrm{T}>300)$.

behavior within 10 min after treatment. At concentrations of 400 and $600 \mu \mathrm{g} /$ liter, the behavioral abnormality was mainly within $30 \approx 40 \mathrm{~min}$. At concentrations of 200 and $800 \mu \mathrm{g} /$ liter, the abnormality was mainly within $10 \approx 20 \mathrm{~min}$; at concentrations between 1,200 and $6,000 \mu \mathrm{g} /$ liter, the abnormality was mainly within $0 \approx 10 \mathrm{~min}$. This result indicates that the lower concentrations might not be able to trigger the abnormality immediately, but at the higher concentrations most of the tested bees were acutely poisoned. Therefore, the concentration of imidacloprid was not only related to the percentage of abnormal foraging behavior but also to the onset of behavioral changes after imidacloprid ingestion.

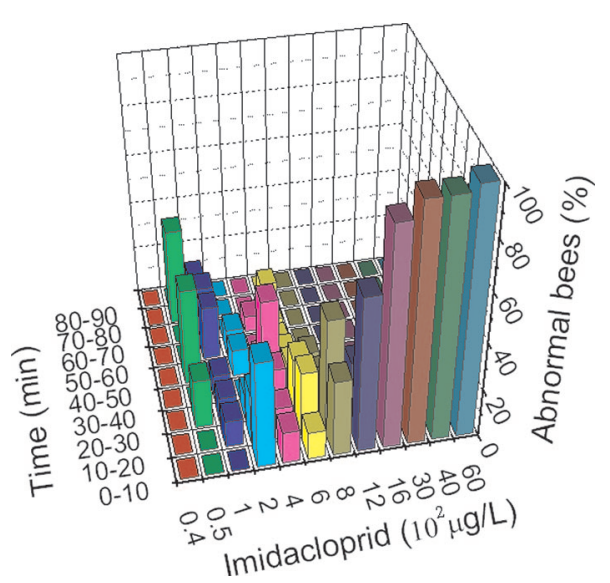

Fig. 7. The access ratio of behavioral abnormality ( $\mathrm{T}>$ $300 \mathrm{~s}$ ) after feeding 50\% sugar water containing different concentrations of imidacloprid. The time frame of observation was divided into $0-10,10-20,20-30,30-40,40-50,50-60$, $60-70,70-80$, and $80-90 \mathrm{~min}$ after treatment. The testing concentrations of imidacloprid are shown in Fig. 3. 


\section{Discussion}

Previous traditional oral lethal dosage measurements for imidacloprid on honey bees showed various $\mathrm{LD}_{50}$ values, ranging from 3.7 to $81 \mathrm{ng}$ per bee ( $\cong 184 \approx 6,000 \mu \mathrm{g} /$ liter), in $48 \mathrm{~h}$ (Elbert et al. 1991; Suchail et al. 2000, 2001; Nauen et al. 2001; Schmuck et al. 2001; Decourtye et al. 2003). The variation of the $\mathrm{LD}_{50}$ value could be attributed to the difference among the colonies (Suchail et al. 2001). Previous studies demonstrated that the feeding activity might be different in different colonies, or even in the same colonies (Page et al., 1995, Bailez 1996). However, the susceptibility to insecticide is also seasonally dependent. Decourtye et al. (2003) showed that the honey bees were more susceptible to imidacloprid in winter than in summer. To avoid the artificial effects caused by the colony, individuals and seasons, the experiments reported in the current study were carried out only on sunny days in the same season. Although some variation in feeding behavior among bee individuals and susceptibility to imidacloprid were observed, our results show that the control honey bees were able to constantly return to the feeding site within $300 \mathrm{~s}$ but that a proportion of the poisoned bees could not. Previous studies by Menzel $(1985,1999)$ pointed out that the interval between bouts of natural foraging cycles may range from minutes to hours, or even days. However, in our case the bees were trained to visit a feeder with sufficient sugar water; thus, the interval could be kept within a certain time range. Because the interval of each treated bee was compared with its own interval before treatment, which was $<300 \mathrm{~s}$, counting the interval between two successive visits of the same bee to the same feeding site was promising for revealing any abnormality of the poisoned honey bee, especially for the sublethal dosage level.

Our results show that the foraging behavior of honey bees can be affected by imidacloprid with concentrations as low as $50 \mu \mathrm{g} /$ liter. Obviously, more honey bees showed abnormal foraging behavior at a higher dosage, and no honey bee could return to the feeding site in the same way as an untreated bee if it was treated with a concentration $>800 \mu \mathrm{g}$ /liter (Fig. 3). This might have been due to these honey bees being disoriented and losing their way to the hive or to the feeding site. Without tracking the flight pathways of the poisoned bees, we cannot be sure where these bees went during the periods that they went missing. However, our observation at the entrance of each beehive did not find any treated bee returning to her beehive. Previous proboscis extension reflex (PER) studies have shown that the honey bee's learning ability could be impaired by imidacloprid treatment (Decourtye et al. 2003, 2004a, 2004b; for review, see Desneux et al. 2007). The foraging activity of the honey bees on the artificial flower device was reduced by insecticides, such as deltamethrin and imidacloprid (Ramirez-Romero et al. 2005). Although the PER experiments demonstrated that short-term memory can be impaired by imidacloprid treatment, the reduction of foraging activity of honey bees on the flower device, as well as the delay in the intervals of return visits, as shown in this study, might be due to the bees' inability to retrieve the long-term memory of their fly pathway to the artificial flower device (Menzel 1999).

The residues of imidacloprid detected in sunflower, Helianthus annuus L.; maize, Zea mays L.; and canola, Brassica napus L. all were < 10 ppb (Schmuck 1999; Wallner et al. 1999; Curé et al. 2000; Schmuck et al. 2001; Wallner 2001; Bonmatin et al. 2003, 2005; Laurent and Rathahao 2003). The lowest observed effect concentration was $50 \mu \mathrm{g} /$ liter, which is $\approx 41.6 \mathrm{ppb}$ (the density of sugar water was 1.2). Because the residue of imidacloprid in the natural environment is low, the honey bee would not be poisoned acutely. Nevertheless, it is still possible for the toxin to accumulate in the honey bee's body to reach the effective dosage through several flower visits and induce abnormal foraging behavior.

In addition, although imidacloprid is one of the systemic insecticides applied for seed dressing, foliate, and soil sprays, the metabolites, such as 5-hydroxy, olefin, 4,5-dihydroxy, desnitro, 6-CAN (6-chloronicotinic acid), and urea are also poisonous to the honey bee (Araki et al. 1994; Nauen et al. 2001; Suchail et al. 2001, 2003). Therefore, a small amount of imidacloprid in the natural environment together with its metabolites may be harmful to the honey bee. However, our pilot tests on DMSO and acetone, the solvents for imidacloprid, also showed a significant difference between the treatment of the two solvents (Fig. 2), indicating that the solvent used for dissolving the active ingredient in the insecticide could be another poisonous factor to the honey bee. To avoid the poisonous effect caused by acetone, the solvent used for dissolving imidacloprid or other insecticides in future experiments should be DMSO.

More than $34 \%$ of bees were missing if they were treated with imidacloprid with a concentration $>600$ $\mu \mathrm{g} /$ liter (Fig. 4), and only half of the missing bees turned back to the feeder the next day if they were treated with 6,000 $\mu \mathrm{g}$ /liter imidacloprid (Fig. 5). For those bees previously treated with 1,200 $\mu \mathrm{g} /$ liter imidacloprid that returned to the feeder the next day, even though they had returned, they did not come to the feeder regularly, and the intervals between bouts might be longer than $300 \mathrm{~s}$ (see Fig. 6), suggesting that the impaired behavior was prolonged and could be attributed to an incomplete recovery from the treatment. This prolonged effect might further influence the survival of the colony. Whether the abnormal foraging behavior is caused by impaired long-term memory is still not known. Nevertheless, our behavioral experiments demonstrated that with the concentration as low as $50 \mu \mathrm{g} /$ liter the bees would lose their way to their hive if they ingested the systematic insecticide naturally. One of the phenomena of colony collapse disorder (CCD) reported recently is that a large amount of bee workers die in the field. The mysterious cause for CCD has been suspected to be some systemic insecticides such as imidacloprid. Measuring the returning time of foraging behavior reported in the current study provides a convenient and 
reliable method to help in the risk assessment of behavioral sublethal effects of pesticides on honey bees.

\section{Acknowledgments}

We thank the anonymous reviewers for insightful corrections and improvements. This work was supported by a project grant (96AS-14.2.2-BQ-B3) from the BAPHIQ (Bureau of Animal and Plant Health Inspection and Quarantine), Council of Agriculture, Executive Yuan, Taiwan.

\section{References Cited}

Araki, Y., W. Bornatsch, A. Brauner, T. Clark, G. Dräger, S. Kurogochi, H. Sakamato, and K. Vogeler. 1994. Metabolism of imidacloprid in plants. Proc. IUPAC Congress, Wash. 2B: 157.

Bailez, O. 1996. Études du comportement de butinage et des capacités de discrimination olfactive dans la relation abeille (Apis mellifera)-colza (Brassica napus L.). Thèse de Doctorat, University of Paris XIII, Paris, France.

Bonmatin, J. M., I. Moineau, R. Charvet, C. Fleche, M. E. Colin, and E. R. Bengsch. 2003. A LC/APCI-MS/MS method for analysis of imidacloprid in soil, in plants, and in pollens. Anal. Chem. 75: 2027-2033.

Bonmatin, J. M., P. A. Marchand, R. Charvet, I. Moineau, E. R. Bengsch, and M. E. Colin. 2005. Quantification of imidacloprid uptake in maize crops. J. Agric. Food Chem. 53: 5336-5341.

Bortolotti, L., R. Montanari, J. Marcelino, P. Medrzycki, S. Maini, and C. Porrini. 2003. Effect of sub-lethal imidacloprid doses on the homing rate and foraging activity of honey bees. Bull. Insectol. 56: 63-67.

Chauzat, M. P., J. P. Faucon, A. C. Martel, J. Lachaize, N. Cougoule, and M. Aubert. 2006. A survey of pesticide residues in pollen loads collected by honey bees in France. J. Econ. Entomol. 99: 253-262.

Curé, G., H. W. Schmidt, and R. Schmuck. 2000. Results of a comprehensive field research programme with the systemic insecticide imidacloprid (Gaucho), pp. 49-59. In L. P. Belzunces, C. Pelissier, and G. B. Lewis [eds.], Hazards of pesticides to bees. Institut National de la Recherche Agronomique, Avignon, France.

Cutler, G. C., and C. D. Scott-Dupree. 2007. Exposure to clothianidin seed-treated canola has no long-term impact on honey bees. J. Econ. Entomol. 100: 765-772.

Decourtye, A., E. Lacassie, and M. H. Pham-Delègue. 2003. Learning performances of honeybee (Apis mellifera $\mathrm{L}$ ) are differentially affected by imidacloprid according to the season. Pest Manag. Sci. 59: 269-278.

Decourtye, A., J. Devillers, S. Cluzeau, M. Charreton, and M.-H. Pham-Delègue. 2004a. Effects of imidacloprid and deltamethrin on associative learning in honeybees under semi-field and laboratory conditions. Ecotoxicol. Environ. Saf. 57: 410-419.

Decourtye, A., C. Armengaud, M. Renou, J. Devillers, S. Cluzeau, M. Gauthier, and M. H. Pham-Delègue. 2004b. Imidacloprid impairs memory and brain metabolism in the honeybee (Apis mellifera L.). Pestic. Biochem. Phys. 78: 83-92.

Desneux, N., A. Decourtye, and J.-M. Delpuech. 2007. The sublethal effects of pesticides on beneficial arthropods. Annu. Rev. Entomol. 52: 81-106.
Elbert, A., B. Becker, J. Hartwig, and C. Erdelen. 1991. Imidacloprid-a new systemic insecticide. Pflanzenschutz-Nachr. Bayer 44: 113-136.

Fahrbach, S. E. 2006. Structure of the mushroom bodies of the insect brain. Annu. Rev. Entomol. 51: 209-232.

Ho, M. W., and J. Cummins. 2007. Mystery of disappearing honeybees. Sci. Soc. 34: 35-36.

Kirchner, W. H. 1999. Mad-bee-disease? Sublethal effects of imidacloprid (Gaucho ${ }^{\circledR}$ ) on the behaviour of honeybees. Apidologie 30: 422.

Laurent, F. M., and E. Rathahao. 2003. Distribution of $\left[{ }^{14} \mathrm{C}\right]$ imidacloprid in sunflower (Helianthus annuus) following seed treatment. J. Agric. Food Chem. 51: 80058010.

Menzel, R. 1985. Learning in honey bees in an ecological and behavioral context, pp. 55-74. In B. Hölldobler and M. Lindauer [eds.], Experimental behavioral ecology. Fischer, Stuttgart, Germany.

Menzel, R. 1999. Memory dynamics in the honeybee J. Comp. Physiol. 185: 185-340.

Nauen, R., U. Ebbinghaus-Kintscher, and R. Schmuck. 2001. Toxicity and nicotinic acetylcholine receptor interaction of imidacloprid and its metabolites in Apis mellifera ( $\mathrm{Hy}$ menoptera: Apidae). Pest Manag. Sci. 57: 577-586.

Oldroyd, B. P. 2007. What's killing American honey bees? PLoS Biol. 5: el68.

Page, R. E., G. E. Robinson, M. K. Fondrk, and M. E. Nasr. 1995. Effects of worker genotypic diversity on honeybee colony development and behavior (Apis mellifera L.). Behav. Ecol. Sociobiol. 36: 387-396.

Pham-Delègue, M.-H., A. Decourtye, L. Kaiser, and J. Devillers. 2002. Behavioural methods to assess the effects of pesticides on honey bees. Apidologie 33: 425-432.

Ramirez-Romero, R., J. Chaufaux, and M.-H. Pham Delègue. 2005. Effects of CrylAb protoxin, deltamethrin and imidacloprid on the foraging activity and the learning performances of the honeybee Apis mellifera, a comparative approach. Apidologie 36: 601-611.

Schmuck, R. 1999. No causal relationship between Gaucho ${ }^{\circledR}$ seed dressing in sunflowers and the French bee syndrome. Pflanzenschutz-Nachr. Bayer 52: 257-299.

Schmuck, R., R. Schöning, A. Stork, and O. Schramel. 2001. Risk posed to honeybees (Apis mellifera L, Hymenoptera) by an imidacloprid seed dressing of sunflowers. Pest Manag. Sci. 57: 225-238.

Suchail, S., D. Guez, and L. P. Belzunces. 2000. Characteristics of imidacloprid toxicity in two Apis mellifera subspecies. Environ. Toxicol. Chem. 19: 1901-1905.

Suchail, S., D. Guez, and L. P. Belzunces. 2001. Discrepancy between acute and chronic toxicity induced by imidacloprid and its metabolites in Apis mellifera. Environ. Toxicol. Chem. 20: 2482-2486.

Suchail, S., L. Debrauwer, and L. P. Belzunces. 2003. Metabolism of imidacloprid in Apis mellifera. Pest Manag. Sci. 60: 291-296.

Thompson, H. M. 2003. Behavioural effects of pesticides in bees: their potential for use in risk assessment. Ecotoxicology 12: 317-330.

Wallner, K. 2001. Test regarding effects of imidacloprid on honey bees. Les Colloques de l'INRA. 98: 91-94.

Wallner, K., A. Schur, and B. Stürz. 1999. Test regarding the danger of the seed disinfectant, Gaucho ${ }^{\circledR} 70 \mathrm{WS}$, for honeybees. Apidologie 30: 423.

Received 1 August 2007; accepted 24 June 2008. 